\title{
Patient Satisfaction with and Use of Telemental Health Services in the Perinatal Period: a Survey Study
}

\author{
Marra Ackerman $^{1}$ (D) $\cdot$ Elizabeth Greenwald ${ }^{2} \cdot$ Paraskevi Noulas $^{1} \cdot$ Christina Ahn $^{1}$ (D)
}

Accepted: 6 December 2020/ Published online: 3 January 2021

(C) The Author(s) 2021

\begin{abstract}
We aimed to assess patients' utilization of and satisfaction with telemental health (TMH) in the perinatal period. We hypothesized that satisfaction with TMH would be at least equal to, if not greater than, with in-person appointments. We conducted a cross-sectional survey between March 2018-June 2019 to evaluate patient satisfaction with and use of TMH services in the perinatal period. Participants used TMH services across the second and third trimester of pregnancy and the first year post-partum. Nearly half of the patients $(8 / 19,42 \%)$ used TMH to see their provider within the first two weeks post-partum. Participants were most commonly in treatment for anxiety $(14 / 19,74 \%)$ and/or depression $(9 / 19,47 \%)$. Most participants agreed or strongly agreed $(13 / 19,69 \%)$ that TMH improved their access to healthcare and that they could see the clinician as well as if they met in person $(14 / 19,74 \%)$. TMH was a highly accepted and appreciated method of mental health care delivery for perinatal women when offered as an alternative to inperson or telephone sessions.
\end{abstract}

Keywords Perinatal $\cdot$ Postpartum $\cdot$ Telemental health $\cdot$ Depression $\cdot$ Anxiety

\section{Background}

Prior to March 2020, telemental health (TMH) was minimally utilized given technological, legal and regulatory concerns [1]. Since the start of the COVID-19 pandemic, mental health treatment has been largely provided via TMH. By in large, providers and patients have quickly learned to adjust to TMH [2]. Pre-pandemic, TMH improved patients' access to care by removing transportation barriers, reducing missed work hours, and relieving caregiver burden of accompanying patients to appointments [3]. Evidence indicates TMH can improve

Marra Ackerman

Marra.Ackerman@nyulangone.org

1 Department of Psychiatry, NYU Grossman School of Medicine, New York, NY, USA

2 Department of Psychiatry, Beth Israel Deaconess Medical Center, Boston, MA, USA 
outcomes including fewer hospital readmissions, better adherence, and shorter hospital stays $[3,4]$. There have been limited available studies of TMH in the perinatal period. In 2017, Wisner et al. showed that telephone-delivered care to women with depression in the postpartum period had comparable positive impact on symptoms and functioning as compared to usual care [5].

More research is needed to explore potential benefits of TMH in the perinatal population [6]. The perinatal period, defined as the 40 week gestational period and first year post-partum, is associated with many stressors including: role transition to motherhood; relationship stressors; schedule changes; and decreased sleep. Physical changes (such as hormonal fluctuations and recovery from labor) also affect patients' mobility and ability to access care. Psychotropic medication regimens may also be changed due to concerns for risk to the fetus or during lactation. The point prevalence of depression during pregnancy is estimated between 11 and 15\% and 13-19\% in the post-partum [7]. The US Preventative Services Task Force recommends screening for depression in pregnant and postpartum women and referring high risk women to counseling interventions [8].

Due to the many challenges associated with the perinatal period, TMH may prove particularly valuable in this population, beyond the current pandemic [9]. TMH can improve patient access to reproductive psychiatrists who may be concentrated in academic medical centers; reduce transportation costs and childcare burdens; and allow for clinical observation of the patient and her baby in their home environment, allowing for a direct assessment of bonding and attachment. As such, in this present study, we aimed to assess patients' utilization of and satisfaction with $\mathrm{TMH}$ in the perinatal period. We hypothesized that satisfaction with $\mathrm{TMH}$ would be at least equal to, if not greater than, with in-person appointments.

\section{Methods}

We conducted a cross-sectional survey between March 2018-June 2019 to evaluate patient satisfaction with and use of TMH services in the perinatal period. Participants were eligible for inclusion if they were female; between the ages of 18-50 years; English speaking; and had utilized TMH health services at NYU Psychiatry Associates during pregnancy and/or the first year post-partum within a year of recruitment. Patients were able to connect with their providers through any device that had a microphone and camera (e.g. smartphone, tablet or desktop) and were able to access their sessions from work or home so long as they were in a private, quiet, and safe space. TMH sessions were conducted via an encrypted HIPAAcompliant platform through the NYULH MyChart portal. Patients were provided with tip sheets assisting them with the login process and help desk contact information for any technical questions or issues. Eligible patients who were informed of the study and agreed to be contacted were invited to complete an online de-identified survey via email using REDCap. The survey required approximately 5-10 min to complete.

The survey began with 18 fields regarding the patient's demographic information, recent pregnancy, and experience using telehealth services. It then included 21 questions adapted from the Telehealth Usability Questionnaire [10], which assessed the usefulness of TMH in the perinatal period; ease of use and learnability; interface quality and reliability; satisfaction with $\mathrm{TMH}$, and plans for future use. Two questions were added that were specific to the postpartum period (see Table 1: questions 22-23). Patients were also asked whether or not they planned to continue to use $\mathrm{TMH}$, and space was provided for additional comments on TMH. 


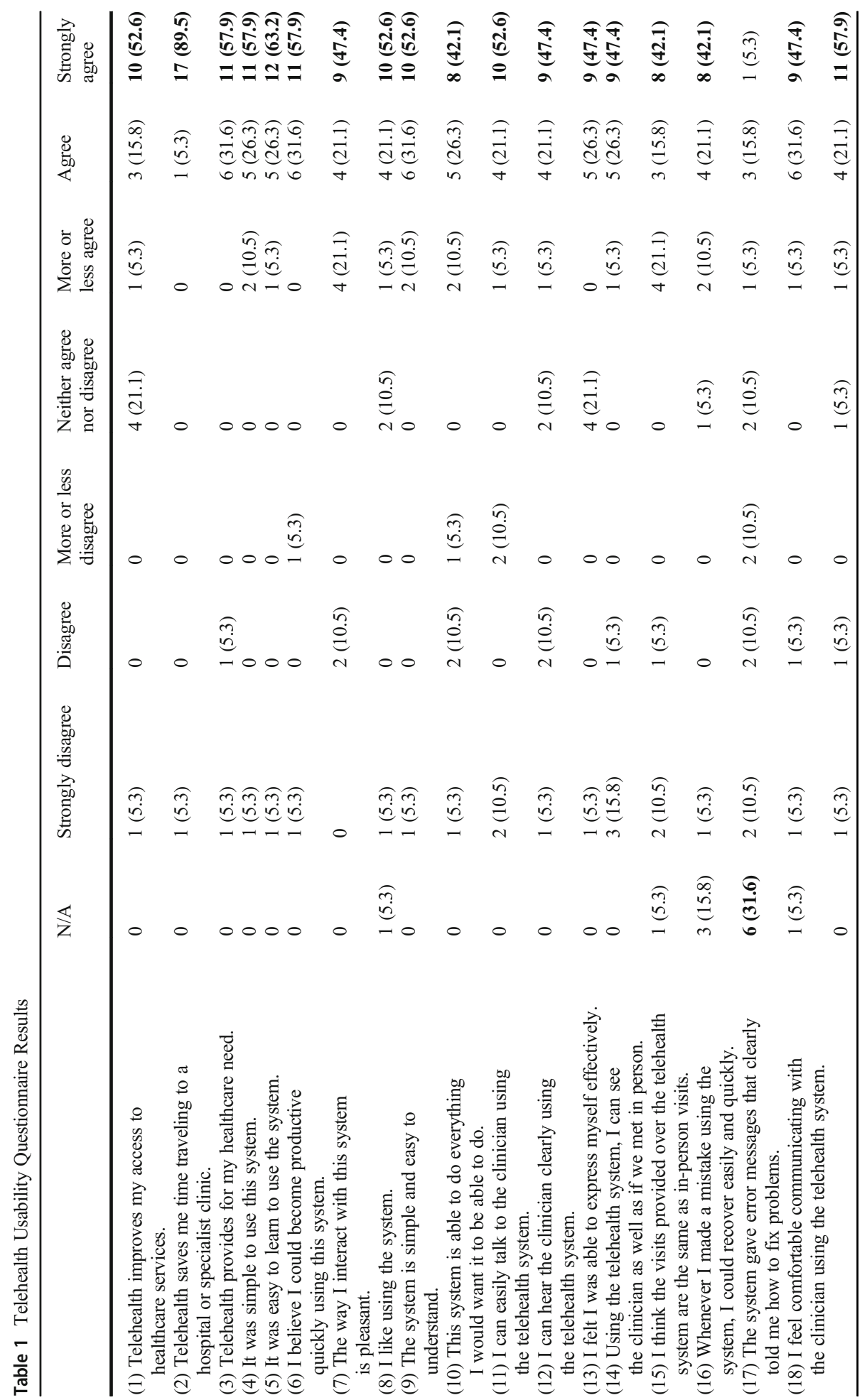




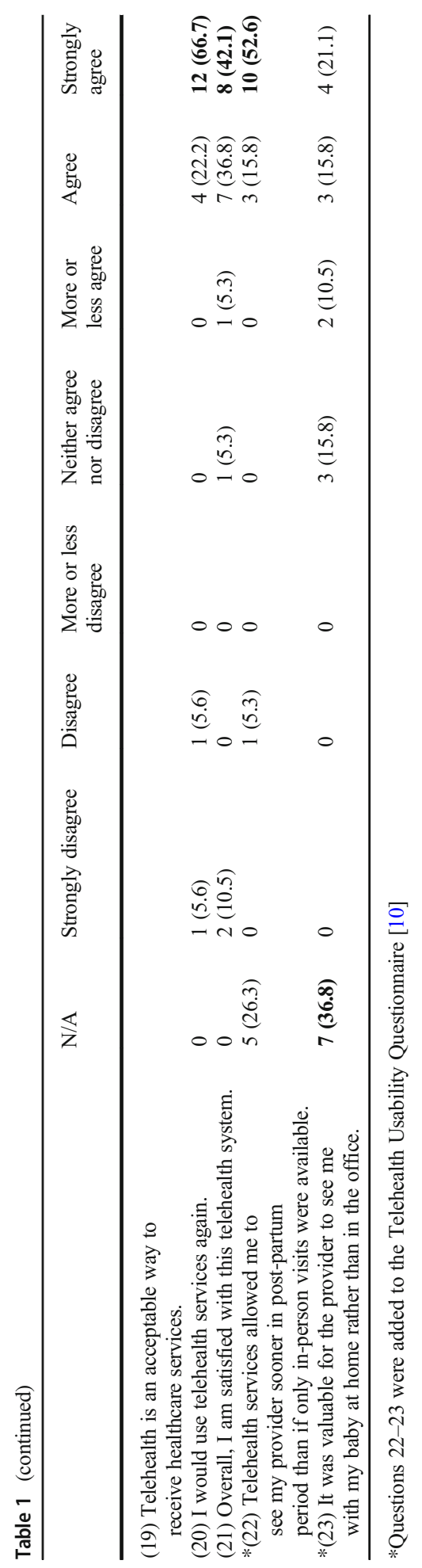


Table 2 Demographic Characteristics

\begin{tabular}{|c|c|c|c|}
\hline Characteristic & & $\begin{array}{l}\text { All Patients } \\
(N=19)\end{array}$ & $\%$ \\
\hline \multirow[t]{3}{*}{ Weeks Pregnant } & N/A (post-partum) & 14 & 73.7 \\
\hline & 2nd trimester (13-27 weeks) & 3 & 15.8 \\
\hline & $3 \mathrm{rd}$ trimester (28-41 weeks) & 2 & 10.5 \\
\hline \multirow[t]{5}{*}{ Months post-partum } & N/A (still pregnant) & 5 & 26.3 \\
\hline & 1 month or less & 3 & 15.8 \\
\hline & $2-6$ months & 5 & 26.3 \\
\hline & $7-12$ months & 4 & 21.1 \\
\hline & More than 12 months & 2 & 10.5 \\
\hline \multirow[t]{3}{*}{ Age } & $26-30$ & 3 & 15.8 \\
\hline & $31-35$ & 13 & 68.4 \\
\hline & $36-40$ & 3 & 15.8 \\
\hline \multirow[t]{2}{*}{ Current marital status } & $\begin{array}{l}\text { Married (or in a domestic } \\
\text { partnership) }\end{array}$ & 18 & 94.7 \\
\hline & Divorced & 1 & 5.3 \\
\hline \multirow[t]{3}{*}{ Current employment status } & Full-time employed & 17 & 89.4 \\
\hline & Homemaker & 1 & 5.3 \\
\hline & Unable to work due to disability & 1 & 5.3 \\
\hline \multirow[t]{2}{*}{ Highest degree of education } & College degree & 8 & 42.1 \\
\hline & Graduate degree & 11 & 57.9 \\
\hline \multirow[t]{3}{*}{ Race/ethnicity } & Caucasian/White & 16 & 84.2 \\
\hline & Black or African-American & 1 & 5.3 \\
\hline & Asian/Pacific Islander & 2 & 10.5 \\
\hline \multirow[t]{3}{*}{ Annual household income } & $50-100,000$ per year & 4 & 21.1 \\
\hline & $101,000-150,000$ per year & 4 & 21.1 \\
\hline & $>200,000$ per year & 11 & 57.8 \\
\hline Distance from NYU Psychiatry & $<5$ miles & 7 & 36.8 \\
\hline \multirow[t]{5}{*}{ Associates 1 Park Ave office } & 5-10 miles & 2 & 10.5 \\
\hline & $11-20$ miles & 6 & 31.6 \\
\hline & 21-30 miles & 1 & 5.3 \\
\hline & $>30$ miles & 2 & 10.5 \\
\hline & I don’t know & 1 & 5.3 \\
\hline Time to travel to NYU Psychiatry & 16-30 minutes & 6 & 31.6 \\
\hline \multirow[t]{3}{*}{ Associates 1 Park Ave office } & $31-45$ minutes & 2 & 10.5 \\
\hline & 46-60 minutes & 7 & 36.8 \\
\hline & $>60$ minutes & 4 & 21.1 \\
\hline \multirow[t]{3}{*}{ Number of children } & 0 & 5 & 26.3 \\
\hline & 1 & 11 & 57.9 \\
\hline & 2 & 3 & 15.8 \\
\hline \multirow[t]{3}{*}{ Mode of delivery for most recent pregnancy } & N/A (still pregnant) & 5 & 26.3 \\
\hline & Vaginal delivery & 9 & 47.4 \\
\hline & C-section & 5 & 26.3 \\
\hline \multirow{4}{*}{$\begin{array}{l}\text { Method of feeding for youngest } \\
\text { child during the first six months }\end{array}$} & N/A (still pregnant) & 5 & 26.3 \\
\hline & Exclusive breastfeeding & 4 & 21.1 \\
\hline & Exclusive bottlefeeding & 4 & 21.1 \\
\hline & Combination of above & 6 & 31.5 \\
\hline \multirow{4}{*}{$\begin{array}{l}\text { Total number of telehealth visits } \\
\text { during pregnancy and the first } \\
\text { year post-partum }\end{array}$} & $1-3$ & 12 & 63.2 \\
\hline & $4-6$ & 2 & 10.5 \\
\hline & $7-10$ & 3 & 15.8 \\
\hline & $>10$ & 2 & 10.5 \\
\hline \multirow{3}{*}{$\begin{array}{l}\text { Type of treatment for which } \\
\text { telehealth services were used }\end{array}$} & Medication management & 4 & 21.0 \\
\hline & Psychotherapy & 3 & 15.8 \\
\hline & Combination of above & 12 & 63.2 \\
\hline Insurance coverage for telehealth services & $\begin{array}{l}\text { Same coverage for telehealth } \\
\text { as for in-person visits }\end{array}$ & 14 & 73.7 \\
\hline
\end{tabular}


Table 2 (continued)

\begin{tabular}{lllr}
\hline Characteristic & & $\begin{array}{l}\text { All Patients } \\
(N=19)\end{array}$ & $\%$ \\
& & No coverage for telehealth or & 2 \\
in-person visits & 3 & 10.5 \\
Planning to continue to & I don't know & 16 & 15.8 \\
use telehealth services & Yes & 3 & 84.2 \\
\hline
\end{tabular}

Survey responses were linked to a de-identified REDCap ID number and were maintained in an encrypted file by a study staff member who was not directly involved in patient care. Descriptive and correlational statistics were used for data analysis.

\section{Results}

From March 2018-June 2019, 45 perinatal patients at NYU Psychiatry Associates were offered TMH; 5 were ineligible due to living out of state, and 8 declined; 32 were surveyed, and 19 responded to the online survey (59\% response rate). Enrollment ended in June 2019. Sociodemographic information is depicted in Table 2. Most patients were between the ages of 31-35 (13/19, 68.4\%), married (18/19, 94.7\%), employed full-time (17/19, 89.5\%), and Caucasian $(16 / 19,84.2 \%)$. The majority of patients were pregnant or had one child $(16 / 19$, $84.2 \%)$. All had at least a college degree. Over half of the patients' reported household income greater than $\$ 200,000(11 / 19,57.9 \%)$, and no patients reported household income less than $\$ 50,000$ per year. More than half of the patients $(11 / 19,57.9 \%)$ would have needed to commute more than $45 \mathrm{~min}$ for an in-office appointment. Most participants used TMH for a combination of medication management and psychotherapy $(12 / 19,63 \%)$. The large majority of patients had the same insurance coverage for TMH as for in-person visits $(14 / 19,74 \%)$.

Participants used TMH services across the second and third trimester of pregnancy and the first year post-partum. Notably, nearly half of the patients $(8 / 19,42 \%)$ used TMH to see their provider within the first two weeks post-partum. Participants were most commonly in treatment for anxiety $(14 / 19,74 \%)$ and/or depression $(9 / 19,47 \%)$ (Supplementary Table 1). As seen in Table 1, most participants agreed or strongly agreed $(13 / 19,69 \%)$ that TMH improved their access to healthcare and that they could see the clinician as well as if they met in person $(14 / 19,74 \%)$. Comments from patients included: "[TMH was] incredibly convenient and necessary for post-partum period. I would not have been able to access care without the teleservice option. The audio was unclear at times, but manageable" and "The telehealth system is very convenient for me to use because I cannot commute with my baby... It makes seeing my doctor of choice a pleasant experience when and where it is best for me."

\section{Conclusions}

Our survey results indicate that TMH in the perinatal period improves access to healthcare; is easy to use and to learn; and provides a satisfying means of accessing mental healthcare. Some clinicians have expressed concern that TMH creates a metaphorical distance between the provider and patient, which may negatively affect patient satisfaction and outcomes. However, 
evidence from multiple studies, including the present study, shows that patients are largely as satisfied with TMH as they are with in-person visits [3, 11]. Randomized controlled trials have also shown equal outcomes for patients utilizing TMH as compared to in-person visits [4, 12].

Many TMH interventions have understandably targeted rural areas to improve access to care. This study highlights the utility of TMH in an urban environment where physical distance may not be an obvious obstacle, but commuting time and travel with an infant can pose significant barriers. TMH offers the opportunity to see women earlier in the post-partum period than is often possible with in-office visits. TMH thereby can provide an opportunity for earlier intervention and for observation of the mother-child dyad in the home environment. The most notable barrier to receiving TMH services was licensing issues which preventing clinicians from providing out of state services. Secondary obstacles were infrequent technical issues and not having TMH set up prior to the immediate postpartum period.

Prior to the COVID-19 pandemic, licensure restriction prevented clinicians from seeing out-of-state patients. Emergency waivers of licensure requirements during the pandemic have helped support treatment continuity and expand access to care. Healthcare providers have been lobbying for an overhaul of the state licensure restrictions as maintaining multiple state licenses is both arduous and expensive.

This study is limited by the relatively small population size and the homogenous nature of the sample as a wealthy, well-educated, Caucasian cohort seen in an academic group practice. However, it is worth noting that TMH services delivered in this study were largely compensated by insurance at the same rate as in-person visits; saved the cost of commuting; and required only a smartphone, tablet, or desktop with access to the internet. Future studies should examine the accessibility of TMH for perinatal women in other sociodemographic and ethnic groups.

In sum, this study illustrates that even prior to the COVID-19 pandemic, TMH was a highly accepted and appreciated method of mental health care delivery for perinatal women when offered as an alternative to in-person or telephone sessions. TMH offers opportunities for earlier intervention and expansion of access to specialized reproductive psychiatric care. The benefits of telemedicine delivered across state lines during the pandemic will hopefully set a precedent that will continue even after emergency clauses are lifted.

Supplementary Information The online version contains supplementary material available at https://doi.org/ 10.1007/s11126-020-09874-8.

\begin{abstract}
Authors' Contributions All authors contributed to the study conception and design. Material preparation, data collection and analysis were performed by Marra Ackerman and Elizabeth Greenwald. Paraskevi Noulas conducted literature review in the area of telemental health and contributed to the selection of the Telehealth Usability Questionnaire and reviewed qualitative data in detail. Marra Ackerman, Paraskevi Noulas, and Christina Ahn all recruited patients to participate in the survey. The first draft of the manuscript was written by Marra Ackerman and Elizabeth Greenwald, and all authors commented on and edited previous versions of the manuscript. Christina Ahn led development of the reference list and formatting responsibilities for the manuscript. All authors read and approved the final manuscript.Data AvailabilityData has been collected and maintained as de-identified data in REDcap.
\end{abstract}

\title{
Compliance with Ethical Standards
}

Conflicts of Interest/Competing Interests The authors have no relevant financial or non-financial interests to disclose. 
Ethics Approval IRB approval was obtained from the NYU School of Medicine, and the study was performed in accordance with the ethical standards as laid down in the 1964 Declaration of Helsinki and its later amendments.

Consent to Participate Informed consent was obtained from all study subjects in accordance with IRB requirements.

Consent for Publication All data has been de-identified to protect patient privacy. No consent required for publication of de-identified data.

Code Availability Not applicable.

Open Access This article is licensed under a Creative Commons Attribution 4.0 International License, which permits use, sharing, adaptation, distribution and reproduction in any medium or format, as long as you give appropriate credit to the original author(s) and the source, provide a link to the Creative Commons licence, and indicate if changes were made. The images or other third party material in this article are included in the article's Creative Commons licence, unless indicated otherwise in a credit line to the material. If material is not included in the article's Creative Commons licence and your intended use is not permitted by statutory regulation or exceeds the permitted use, you will need to obtain permission directly from the copyright holder. To view a copy of this licence, visit http://creativecommons.org/licenses/by/4.0/.

\section{References}

1. Abrams J, Sossong S, Schwamm LH, Barsanti L, Carter M, Kling N, et al. Practical issues in delivery of clinician-to-patient Telemental health in an Academic Medical Center. Harv Rev Psychiatry. 2017;25(3): 135-45.

2. Chen JA, Chung WJ, Young SK, Tuttle MC, Collins MB et al (2020) COVID-19 and telepsychiatry: early outpatient experiences and implications for the future. Gen Hosp Psychiatry 66:89-95. Available from: https://doi.org/10.1016/j.genhosppsych.2020.07.002.

3. Waugh M, Voyles D, Thomas MR. Telepsychiatry: benefits and costs in a changing health-care environment. Int Rev Psychiatry. 2015;27(6):558-68.

4. Hilty DM, Ferrer DC, Parish MB, Johnston B, Callahan EJ, Yellowlees PM. The effectiveness of telemental health: a 2013 review. Telemed J E Health. 2013;19(6):444-54.

5. Wisner KL, Sit DKY, McShea M, Luther JF, Eng HF, Dills JL, et al. Telephone-based depression Care Management for Postpartum Women: a randomized controlled trial. J Clin Psychiatry Nov/Dec. 2017;78(9): $1369-75$.

6. Nair U, Armfield NR, Chatfield MD, Edirippulige S (2018) The effectiveness of telemedicine interventions to address maternal depression: a systematic review and meta-analysis. J Telemed Telecare 24(10):639-650. Available from: https://doi.org/10.1177/1357633X18794332.

7. Howard LM, Molyneaux E, Dennis CL, Rochat T, Stein A et al (2014) Non-psychotic mental disorders in the perinatal period. The Lancet 384(9956):1775-1788. Available from: https://doi.org/10.1016/S01406736(14)61276-9.

8. US Preventive Services Task Force (2019) Interventions to Prevent Perinatal Depression: US Preventive Services Task Force Recommendation Statement. JAMA 321(6):580-587. Available from: doi:https://doi. org/10.1001/jama.2019.0007

9. van den Heuvel JF, Groenhof TK, Veerbeek JH, van Solinge WW, Lely AT et al (2018) eHealth as the next-generation perinatal care: an overview of the literature. J Med Internet Res Jun 5;20(6):e202. Available from: doi: https://doi.org/10.2196/jmir.9262.

10. Parmanto B, Lewis AN, Graham KM, Bertolet MH. Development of the Telehealth usability questionnaire (TUQ). Int J Telerehabil. 2016;8(1):3-10.

11. Malhotra S, Chakrabarti S, Shah R (2013) Telepsychiatry: promise, potential, and challenges. Indian J psychiatry 55(1):3-11. Available from: https://doi.org/10.4103/0019-5545.105499.

12. García-Lizana F, Muñoz-Mayorga I (2010) What about telepsychiatry? A systematic review. Prim Care Companion J Clin Psychiatry 12(2):PCC.09m00831. Available from: https://doi.org/10.4088/PCC. 09m00831whi. 
Publisher's Note Springer Nature remains neutral with regard to jurisdictional claims in published maps and institutional affiliations.

Marra G. Ackerman, MD is Clinical Associate Professor at the New York University (NYU) Grossman School of Medicine and the Director of the Consultation-Liaison Psychiatry Service at NYU Langone Manhattan. In 2005, Dr. Ackerman completed her undergraduate studies at Emory University, where she majored in Biological Anthropology, graduating Phi Beta Kappa, a Fulbright Award finalist, and a Goodrich C. White Merit Scholar. In 2010, Dr. Ackerman obtained her Medical Degree at the NYU Grossman School of Medicine, graduating Alpha Omega Alpha (AOA). Subsequently, in 2014, she completed an internship and residency in general adult psychiatry at the New York State Psychiatric Institute/Columbia University Medical Center, where she was a Chief Resident. During this time, Dr. Ackerman earned the Gold Humanism in Medicine Award, the Barbara Ann Liskin Award, and the Ginsberg Fellowship Award from the American Association for Directors of Psychiatric Residency Training. In June 2015, Dr. Ackerman completed fellowships in Psychosomatic Medicine and in Women's Mental Health at the New York State Psychiatric Institute/Columbia University Medical Center. During this time, she was designated a William Webb Fellow by the Academy of Psychosomatic Medicine. Subsequently, she achieved Board Certification in Psychosomatic Medicine. In July 2015, Dr. Ackerman joined the NYU Department of Psychiatry Faculty Group Practice (FGP) where she oversaw the Women's Mental Health Program and then went on to assume leadership roles as Director of the Psychiatry Faculty Group Practice (FGP) and of the Medical Student and House staff Mental Health Program. She assumed the Director for of the CL Psychiatry in September 2020.

Elizabeth Greenwald , MD, MSc, is currently a second year psychiatry resident at Beth Israel Deaconess Medical Center in Boston, MA. She completed her undergraduate studies at Wesleyan University in 2012, where she majored in English and Biology, graduating Phi Beta Kappa. In 2019, she completed her dual Medical Degree and Master's of Science in Clinical Investigation at New York University School of Medicine.

Paraskevi Noulas, PsyD, is currently the Telepsychiatry Director and a Clinical Assistant Professor of Psychiatry at New York University Grossman School of Medicine. She graduated from the University of Pennsylvania in 2002 where she concentrated on Classical Studies and Psychology. She then spent two years at the Crisis Resource Center at MHA of NYC focusing on 9/11 research and treatment. Dr. Noulas obtained her doctorate from the Graduate School of Applied and Professional Psychology at Rutgers University, specializing in child and adult clinical psychology. Upon completing the early childhood track internship in 2008 at the Jewish Board of Family and Children's Services, she began her post-graduate research fellowship at Yale University and the National Center for PTSD. In 2010, she became the trauma track internship director for the Newington campus at VA Connecticut and provided telemental health care for the Stamford and Danbury integrative clinics. In 2015, she transitioned to the Military Family Clinic at NYU Langone and started NYULH's first medical record based telemental health program. In 2017, her role expanded to Telepsychiatry Director for the Department of Psychiatry, eventually growing the program to include all outpatient and inpatient divisions and the residency training program. She continues to provide supervision and didactics for the residents in CBT, telemental health and attachment as well as provides clinical services at the Faculty Group Practice.

Christina Ahn, MD is currently a Clinical Assistant Professor of Psychiatry at NYU Grossman School of Medicine. She graduated from Harvard College in 2005, where she concentrated in Government and Studies of Women, Gender and Sexuality. Following graduation, she conducted public health research for two years in the Emergency Medicine Department at Massachusetts General Hospital before attending Vanderbilt School of Medicine. Following completion of her medical degree in 2011, Dr. Ahn entered psychiatry residency training at NYU, where she also served as Chief Resident and completed her fellowship in Women's Mental Health. She then served as the Associate Program Director for the NYU Adult Psychiatry Residency Training Program from 2016 to 2018. She currently teaches didactics on supportive psychotherapy and women's mental health to the NYU residents and maintains a private practice. 